\title{
Taking ownership of climate change: participatory adaptation planning in two local case studies from California
}

\author{
Susanne C. Moser • Julia A. Ekstrom
}

Published online: 29 March 2011

(C) The Author(s) 2011. This article is published with open access at SpringerLink.com

\begin{abstract}
Interest in adaptation among local and state governments in the USA is on a steep incline since about 2007. Yet, place-specific vulnerability and adaptation research in the USA is still sparse, the public in many regions is still skeptical about the reality of climate change, and model adaptation planning processes are not wellknown among practitioners. Against this backdrop of growing interest in adaptation, there is a great need to chronicle and critically assess emerging adaptation planning processes to learn broader lessons and share them widely both in the science and in the practice communities. This paper describes and critically evaluates a pilot project tested in two California local communities-San Luis Obispo and Fresno Counties - to illustrate how active engagement of local government and other stakeholders with experts can advance adaptation planning. The approach taken in this project proved to be an effective "conversation opener" in communities not previously engaged in adaptation planning or where political support to address climate change is low. It created a sense of expectation and accountability among local leaders and stakeholders. It also gave local leaders a chance to take ownership of the process and of the issue; it succeeded in raising interest in adaptation planning and increasing understanding of adaptation and that it is needed as much as mitigation. It helped develop an initial set of adaptation strategies for key climate-sensitive sectors, but to be taken up into ongoing policy processes and implemented by localities, requires state and federal funding.
\end{abstract}

S. C. Moser $(\square)$

Susanne Moser Research and Consulting,

Santa Cruz, CA 950604, USA

e-mail: promundi@susannemoser.com

J. A. Ekstrom

Climate and Energy Policy Institute, University of California,

Berkeley, CA 94705, USA
Keywords Participation · Planning process - Climate change $\cdot$ Adaptation $\cdot$ Local government

\section{Introduction}

In 2010, the US National Research Council published a series of studies entitled America's Climate Choices. One of the four components of that congressionally mandated project focused on adaptation to climate change (National Research Council 2010a). It synthesized lessons learned from the efforts to date in planning and preparing for climate change impacts in the USA at local, state, federal, and tribal governance levels as well as in the private and civic sectors. It also laid out an ambitious research and policy agenda for the country. Among its ten recommendations is one directed at local governments:

Local governments should develop and implement climate change adaptation plans pursuant to the national climate adaptation strategy [elsewhere recommended in that report], in consultation with the broad range of stakeholders in their communities. [...]

(National Research Council 2010a, pp. 229-230)

This call to action emerged from the experience gained by the still-small number of US municipalities that have launched adaptation planning efforts, and the very limited stakeholder engagement in them to date, but also from the observation that the much larger group of communities in America has not even begun an adaptation planning process at all (Brody et al. 2010).

Interest in adaptation among local and state governments in the USA has risen only very recently. After the publication of the 2007 assessment of the Intergovernmental Panel on Climate Change, adaptation showed a steep rise in public discourse (Moser 2009a). Some governments 
have begun to take seriously that a comprehensive response to the growing climate risks would need to include greenhouse gas emission reductions and measures to adapt to the impacts. Yet, place-specific vulnerability and adaptation research in the USA is still sparse, the public in many regions still skeptical about the reality of climate change, and model adaptation planning processes not well-known (National Research Council 2010b, c).

Against this backdrop of growing interest in adaptation among US government officials - especially at the local level where resources are most constrained - there is a great need to chronicle and critically assess emerging adaptation planning processes so as to learn broader lessons and share them widely both in the science and in the practice communities.

This paper aims to do just that: describe in sufficient detail and critically evaluate a pilot project tested in two California local communities to illustrate how participation of local government and other stakeholders can advance adaptation planning. Participatory adaptation processes seem to be increasingly practiced and documented in developing country contexts (in "community-based adaptation" and related disaster mitigation and development efforts, see e.g., Allen 2006; Dumaru 2010; Huq and Reid 2007; Reid et al. 2009; Roberts 2010), and have been practiced elsewhere in developed nations such as the UK, Australia, and Canada (e.g., Armitage 2005; Cohen 1997; Few et al. 2007; Ridder and Pahl-Wostl 2005; Salter et al. 2010; Shackley and Deanwood 2002; Shaw et al. 2009; van Aalst et al. 2008). Practical experience with broad stakeholder engagement in adaptation planning in the USA lags significantly behind, however, with few notable exceptions (e.g., Brunner and Lynch 2010; Ebi and Semenza 2008; Frazier et al. 2010). By documenting and evaluating our own experience, we hope to contribute to that growing body of experiential knowledge and scientific understanding, and share the lessons learned with a rapidly growing audience of local officials.

\section{The project approach}

Project background: overview, selection of pilot cases, and collaborating partners

In 2009, upon initiation by the Geos Institute (previously called the National Center for Conservation Science and Policy), ${ }^{1}$ the Local Government Commission obtained funding from the Kresge Foundation to conduct a project

\footnotetext{
${ }^{1}$ We include the former name of the institution here as this is how it was known to the collaborating partners and communities for much of the project duration. The organization was renamed in late October 2010. The Geos Institute is a nonprofit conservation organization based in Ashland, Oregon (for more information about the organization or their climate-related work, see http://www.geosinstitute.org/).
}

entitled "Integrating Climate Change Preparation Strategies across Socioeconomic and Natural Resource Sectors." This project had three interrelated goals: (1) to facilitate the development of multi-sector climate change adaptation strategies by community leaders and local scientific experts; (2) to increase the understanding of local/regional decision-makers about the impacts of climate change and the specific measures they can take to prepare for as well as mitigate these impacts; and (3) to contribute to the growing body of climate change adaptation strategies that can lead to meaningful local, state and federal strategies, policies, and regulations. The project involved original research (downscaled climate change projections and ecological impacts modeling [Koopman et al. 2010a, b] as well as socioeconomic vulnerability assessments [Moser and Ekstrom 2010a, b]) and a series of workshops with stakeholders in two California communities. Both the research and the stakeholder workshops were intended as direct assistance to these local governments with adaptation planning.

The two locations selected for this effort were San Luis Obispo (SLO) County and Fresno County (Fig. 1). Selection criteria included the initiating organizations' preexisting relationships with these localities, the presence of diverse ecological systems, existence of climate-sensitive industries and economic sectors, this project's fit with the timing of ongoing policy developments, and local officials' support for the collaboration (Table 1). An additional motivation was to select locations that together represented a variety of economic industries and climate change stressors so as to serve as useful pilot projects for potential future replication of the approach elsewhere. SLO County, for example, is economically dependent on coastal recreation and tourism, as well as small farms, cattle ranching, and grape growing inland with accompanying wine tourism (Research Department of the San Luis Obispo Chamber of Commerce SLOCC 2009). By contrast, Fresno County, as part of California's Central Valley, is economically dominated by large-scale agriculture, but also contains significant portions of protected federal land owned and managed by the US Department of the Interior (including the Sierra National Forest and Kings Canyon National Park).

The Local Government Commission (LGC) is a nonprofit, nonpartisan membership organization of local government officials and community leaders, based in Sacramento, California, that specializes in assisting local governments "in developing and implementing policies and program that help establish more livable, healthy, prosperous and resource-efficient communities" (http://www.lgc. org/whatwedo/index.html). Its mission is to assist local governments in establishing and nurturing " $\mathrm{a}$ healthier human and natural environment, a more sustainable economy, an actively engaged populace, and an equitable society." LGC works on an ongoing basis with elected 
Fig. 1 Project locations: the counties of San Luis Obispo and Fresno in California (county maps are at the same scale)

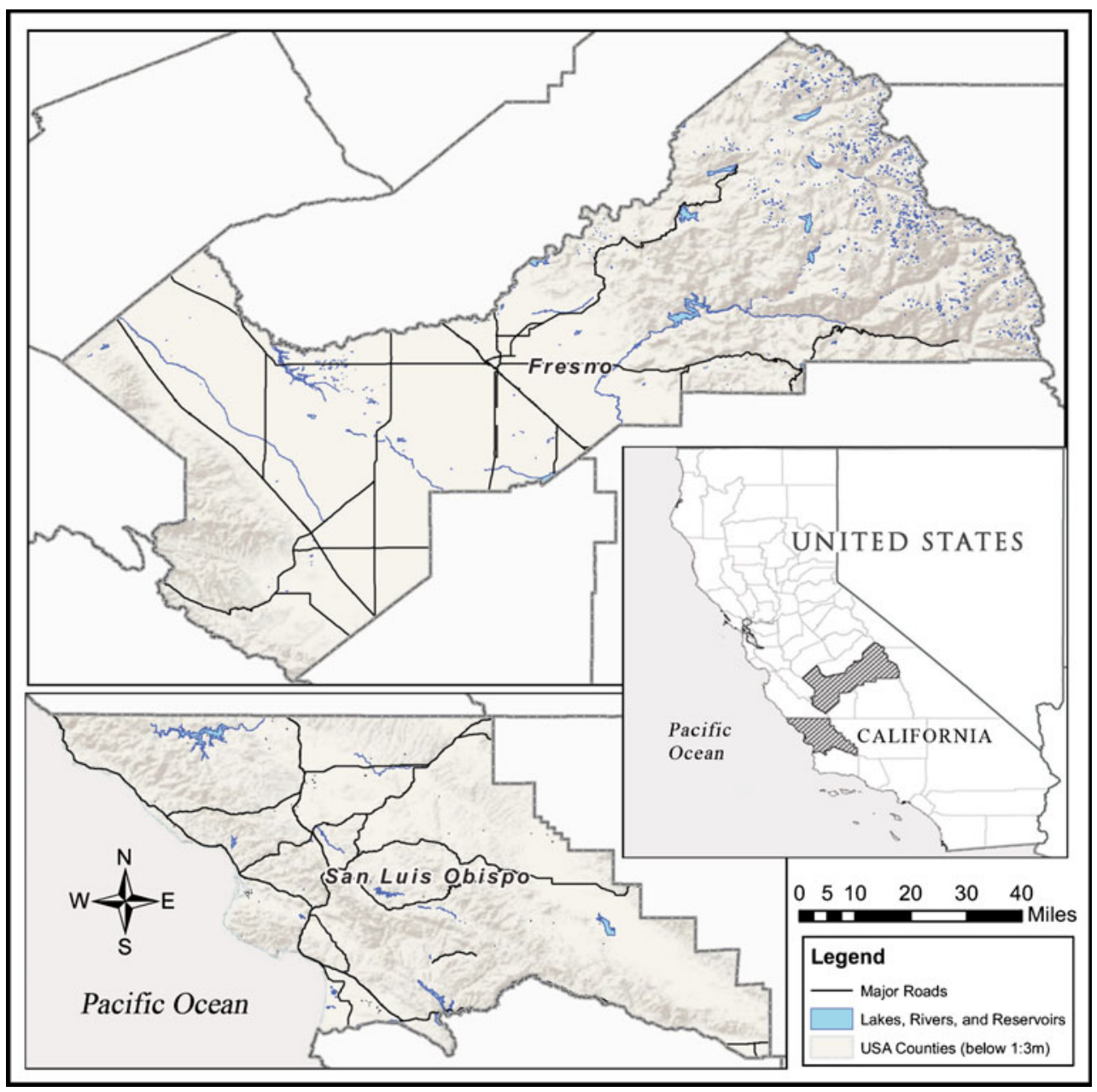

Table 1 Selection criteria underlying the choice of pilot cases

\begin{tabular}{|c|c|c|}
\hline Selection criteria & San Luis Obispo County & Fresno County \\
\hline $\begin{array}{l}\text { Ecology and biological } \\
\text { diversity }^{\mathrm{a}}\end{array}$ & $\begin{array}{l}\text { Plains, coastal habitats (coastal wetlands, beaches, } \\
\text { rocky coast) }\end{array}$ & Sierra Nevada Mountain Range, Central Valley \\
\hline $\begin{array}{l}\text { Protected areas with species } \\
\text { and habitats of concern }{ }^{\mathrm{a}}\end{array}$ & $\begin{array}{l}\text { Carrizo Plain National Monument; Los Padres } \\
\text { National Forest; Santa Lucia, Garcia and Machesna } \\
\text { Mountain Wilderness Areas }\end{array}$ & $\begin{array}{l}\text { Sierra National Forest, Kings Canyon National Park, } \\
\text { Sequoia National Forest }\end{array}$ \\
\hline $\begin{array}{l}\text { Timing with policy planning } \\
\text { (ongoing planning work } \\
\text { related to climate change) }\end{array}$ & $\begin{array}{l}\text { County Climate Action Plan process was initiated prior } \\
\text { to climate change adaptation workshop series; had } \\
\text { completed update to conservation element of the } \\
\text { County's General Plan }\end{array}$ & $\begin{array}{l}\text { City of Fresno had completed a Climate Action Plan; } \\
\text { the wider region had completed the San Joaquin } \\
\text { Valley Blueprint, which included many of the same } \\
\text { people and sectors (and goals) as involved in } \\
\text { adaptation planning; California State University- } \\
\text { Fresno had completed a climate impacts summary } \\
\text { (Harmsen et al. 2008) }\end{array}$ \\
\hline Existing connections & $\begin{array}{l}\text { Local Government Commission had previously } \\
\text { worked with elected officials }\end{array}$ & $\begin{array}{l}\text { Geos Institute had worked with regional district of the } \\
\text { US Forest Service; Local Government Commission } \\
\text { had repeatedly worked with elected officials and staff }\end{array}$ \\
\hline $\begin{array}{l}\text { Major climate-sensitive indus- } \\
\text { tries }\end{array}$ & Tourism and recreation, agriculture & Agriculture \\
\hline Major climate-relevant issues & Water supply, coastal development & $\begin{array}{l}\text { Surface and ground water supply, environmental justice, } \\
\text { public health }\end{array}$ \\
\hline
\end{tabular}

\footnotetext{
${ }^{\mathrm{a}}$ The aim was to ensure a variety of systems in each location and together, across both locations, so as to maximize learning opportunities and relevance for future projects
} 
officials and staff of county and city governments and other community leaders throughout California, giving workshops, providing trainings, guidebooks and technical resources, facilitating networking opportunities and conferences. The GEOS Institute invited LGC to partner in this project given LGC's expertise in convening workshops (including a statewide series on local climate change mitigation), existing relationships with local political leaders in California, and its desire to move into the adaptation arena.

The authors of this paper were contracted by LGC to assist in developing the workshop series and to provide a social vulnerability assessment for each location that served as background information for the discussions with stakeholders. Our perspective here is thus as social scientists providing scientific input into the process, as partners in preparing and facilitating the social systems workshops, and as participant observers of a stakeholder-intensive adaptation planning process. We acknowledge the integral part of Geos Institute's contribution to the overall project (particularly, its leadership on the natural systems workshops), but focus this paper only on the portion of the project, in which we were directly involved, namely the social systems workshop and follow-up events. ${ }^{2}$

\section{Background research}

Two main assessments provided the informational foundation for the workshops in each location. Firstly, the Geos Institute conducted a climate change impacts assessment using downscaled climate projections produced by collaborators at the US Forest Service to develop information on changing temperatures, precipitation, shifts in vegetation, frequency, and extent and severity of wildfire (Koopman et al. 2010a, b). Sea-level rise projections were drawn from work by USGS (Knowles 2009). ${ }^{3}$ These reports formed the basis for a stakeholder workshop focused on climate change risks to natural systems and potential adaptation strategies.

The social system vulnerability assessments described the social systems of each county (its people, economic sectors, and critical infrastructure and community services) and explored their potential vulnerabilities to the impacts of climate change (Moser and Ekstrom 2010a, b; footnote 3). The reports served to initiate thinking about adaptation strategies by providing a vulnerability-focused framework for the discussion. Analyses were based on a wide range of information sources (city, county, regional, state, and

\footnotetext{
${ }^{2}$ The Geos Institute is conducting its own project evaluation, and the reader is referred to the organization's website for further information.

${ }^{3}$ The detailed findings for SLO are available at http://www.lgc.org/ adaptation/slo/; the detailed findings for Fresno are available at http:// www.lgc.org/adaptation/fresno/).
}

federal agency data on demographic, housing, public health, and environmental trends), and included, but were not limited to, a social vulnerability assessment using 2000 Census data and the Social Vulnerability Index methodology proposed by Cutter et al. (2003). The reports provided the necessary background information for workshops with county and community leaders and other local experts to begin developing strategies for climate change adaptation in social systems.

\section{The process}

The natural systems report and workshop preceded the social systems report and workshop in both cases. Overlap was created by inviting some of the natural system stakeholders to the social systems workshop. This was very successful in Fresno, less so in SLO. The workshops produced a first set of recommendations that the project organizers summarized and brought into a subsequent forum with decision-makers, and-in the case of SLO-also a public workshop. A final report summarizing the threats from climate change to natural and social systems and the most prominent adaptation strategies developed through this series of workshops concluded the project. The adaptation planning process is continuing at the time of this writing (section "Evidence of Attitude Changes and Adaptation Progress"). Below we describe the three process components in which we were involved in more detail.

Social systems stakeholder workshops The social systems workshops occurred several weeks to about two months after the natural systems workshops in each location, respectively. Project director (and executive director of LGC), Judith Corbett, and project manager Kate Meis held the lead role for organizing and facilitating the social system workshops and follow-up events. The Geos Institute partner and the authors, however, were intimately involved in identifying potential invitees, presenting background information, and facilitating group discussions. In SLO, LGC additionally worked with a professional facilitator to guide the stakeholder workshop.

The workshop was designed to place local officials (typically a county supervisor, city manager, mayor, or elected council member) immediately at the center of the process as hosts and prominent leaders. After presentations of background information, the majority of the day was spent in facilitated small-group discussions (typically with a sector focus, but also cross-sectoral interaction) to deepen everyone's understanding of the components of vulnerability (exposure, sensitivity and adaptive capacity), and identify possible adaptive interventions to increase resilience in the face of climate change. The slightly longer 
workshop in SLO included a prioritizing exercise at the end of the workshop and a group debrief.

LGC had the lead responsibility for inviting stakeholders to the social systems workshop. Representatives were identified from relevant local to federal agencies as well as non-governmental and private-sector organizations in any of the issue areas identified as particularly climatesensitive and vulnerable. LGC built on this initial list with natural systems workshop attendees, its own local contacts and input from an informal local advisory team to ensure key actors were not overlooked. Effort was made to ensure adequate and relatively even sectoral representation. In Fresno, numerous stakeholders attended the natural and social systems workshops, which facilitated cross-sector integration and priority setting of adaptation options. About 40 people attended the workshops in each location, which achieved a reasonable balance between broad representation and manageable size for good participant interaction.

Decision-maker forums LGC's longstanding experience in working with local governments in California contributed an important dimension to the project. They organized a follow-up event with decision-makers after the two stakeholder workshops. The rationale was that such an event would make official adoption of an adaptation strategy and implementation more likely as elected officials and other decision-makers could serve as champions and take ownership of the strategies emerging from the process. Thus, several weeks after the social systems workshop was completed, a forum for decision-makers was held in each location. While the Geos Institute partner (in the case of SLO), or a local climate scientist (in the case of Fresno) and one of the authors (JE) presented brief summaries of projected climate changes, impacts on natural systems, and social system vulnerabilities, stakeholders involved in previous workshops were there to present the draft adaptation options.

Public workshop Finally, in SLO, a capstone public workshop was held to bring the issue of climate change impacts and adaptation needs and opportunities to the broader community. Due to significant support from local elected officials, such a public event was deemed useful. The event dovetailed with the local Climate Action Plan development process begun in May 2010. A public workshop was not conducted in Fresno County because it was felt that public acceptance and awareness of climate change would need to be advanced more before there would be a readiness to engage the broader community in adaptation planning. The workshop series in Fresno also occurred close to the November 2010 national elections, with one of the political propositions on the ballot calling for a suspension of California's Global Warming Solutions
Act (AB 32). LGC and local Fresno collaborators felt timing was not fruitful for constructive public engagement at the time.

\section{Evaluation}

The subjective nature of evaluation

Evaluating the effectiveness of stakeholder engagement in any assessment, planning, or decision-making process is challenging and inherently subjective (Moser 2009b; National Research Council 2008; Warburton et al. 2011). The process was also not deliberately set up as an experiment to test what factors invoked different degrees of outcome. In addition to our previously mentioned roles, one of us (SM) developed a post-workshop evaluation survey. Thus, our evaluation is biased by our roles and perspectives, and conducted from an insider perspective rather than from that of a neutral, outside observer. This bias notwithstanding, we can present observations, results of the survey, and insights gleaned from subsequent informal interviews with key players in each location as a basis for critical reflection of the process' effectiveness.

Regionally adjusted goals of the adaptation planning process

Importantly, all evaluation requires that achievements be judged against intended outcomes. As mentioned above, the goals of the process were threefold:

- to facilitate the development of multi-sector climate change adaptation strategies by community leaders and local scientific experts;

- to increase the understanding of local/regional decisionmakers about the impacts of climate change and the specific measures they can take to prepare for as well as mitigate these impacts; and

- to contribute to the growing body of climate change adaptation strategies that can lead to meaningful local, state and federal strategies, policies, and regulations.

Once the cases were selected, these goals were flexibly adjusted to fit the ongoing policy and planning processes encountered in each while ensuring that the project met the larger missions and goals of each of the participating organizations. For example, SLO County had recently begun developing a Climate Action Plan (prior to our arrival solely focused on mitigation) with key stakeholders and the public. Thus, the more specific objective for this case became to merge our stakeholders-driven adaptation planning process with the county's process to develop a more comprehensive Climate Action Plan. By contrast, in 
Fresno County - a politically conservative region of California - political acceptance and interest in working on the topic of climate change was extremely low. Prior to our involvement, however, the County had been involved in a regional planning process, that aimed to limit sprawl and create a healthier, greener, economically vibrant, and more sustainable region overall (Council of Fresno County Governments 2009). Thus, one of the principal goals here (especially of the social systems workshop) was to link adaptation planning to those efforts, primarily in the form of affirmations, modifications, and modest additions to those existing strategies.

Informally, the authors had two other goals and research interests in addition to the three overarching ones, namely (a) to assess whether or not local officials and stakeholders would be able to quickly pick up on and adopt an unfamiliar social science concept like vulnerability, and (b) to judge the usefulness of vulnerability as a way to frame discussions of adaptation options, especially in politically contentious or climate change-skeptical settings.

\section{Evaluation methods and data}

Three pieces of information, gathered through three different approaches respectively, inform our evaluation of the workshop series. Firstly, we gathered qualitative information through participant observation during the workshops and the project team debriefings after the events. One of us (JE) attended all but one of the workshops, while the other (SM) participated only in the social systems workshops in each location. The second source of information for our evaluation stems from a web-based survey administered immediately after the social systems workshops to attendees. ${ }^{4}$ The intent of the survey was to obtain fresh feedback on the events to assess people's reactions to both the content and facilitated discussions. Finally, one of us (JE) conducted informal follow-up conversations with key team members and local contacts in each county to learn about impacts of the process on policy developments in the interim. These conversations revealed the existence or absence of continued interactions, meetings, plans and projects between the two counties and LGC, and thus provided evidence on whether or not short-term objectives had been achieved and how the process had affected the local climate change conversation and/or increased the motivation for continuing the adaptation planning process. Together these three sources of data allow us to judge whether the formal and informal project objectives have been met and to triangulate what worked well and what

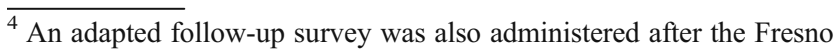
decision-maker forum. Space allows only for discussion of qualitative results.
}

could be improved in future participatory climate change adaptation processes.

\section{Results}

Workshop observations and feedback

\section{SLO County}

In San Luis Obispo, 43 individuals attended the social systems workshop. It involved key city and county leaders and several local agency directors to provide links to ongoing mitigation planning efforts. After a project overview, workshop participants received a briefing on local climate change impacts and learned about the outcomes of the natural systems workshop. A tutorial on vulnerability and its underlying drivers, an overview of the county's social, economic and infrastructure vulnerabilities (based on Moser and Ekstrom 2010a), and on adaptation as a necessary and complementary climate risk management strategy to mitigation followed. Workshop participants had an opportunity to ask questions, which immediately offered an opportunity to illustrate the benefits of stakeholder input into the entire adaptation planning process. Already, during the pre-workshop peer review of the social systems background report, knowledgeable locals identified a possible misreading of Census data underlying the social vulnerability index. Reviewers pointed out that the most vulnerable group according to our calculations-namely students living near the state university, Cal Poly, in the City of San Luis Obispo-were hardly "low income" (the factor that most drove the vulnerability in that location). We used that example to engage stakeholders' local knowledge of that area and to point out what they could offer that cannot be obtained from data alone. This encouraged participants to identify other, more detailed information to bring the analysis "to life."

In the structured and facilitated break-out group discussions in sector-focused groups of about eight to ten individuals that followed, attendees further deepened their understanding of exposures, sensitivities, and adaptive capacities. Participants had been pre-assigned to these groups based on expressed interest and expertise. Thus, significant local knowledge and geographic specificity could be added. After a mid-day break, sector groups briefly summarized their findings for other workshop participants before returning to the brainstorm of specific strategies to intervene to reduce exposure, sensitivity, and/ or increase adaptive capacity (Fig. 2). Groups identified existing measures, programs, policies or laws that could be used to implement adaptation, identified what additionally would be required to realize a particular adaptation option, 


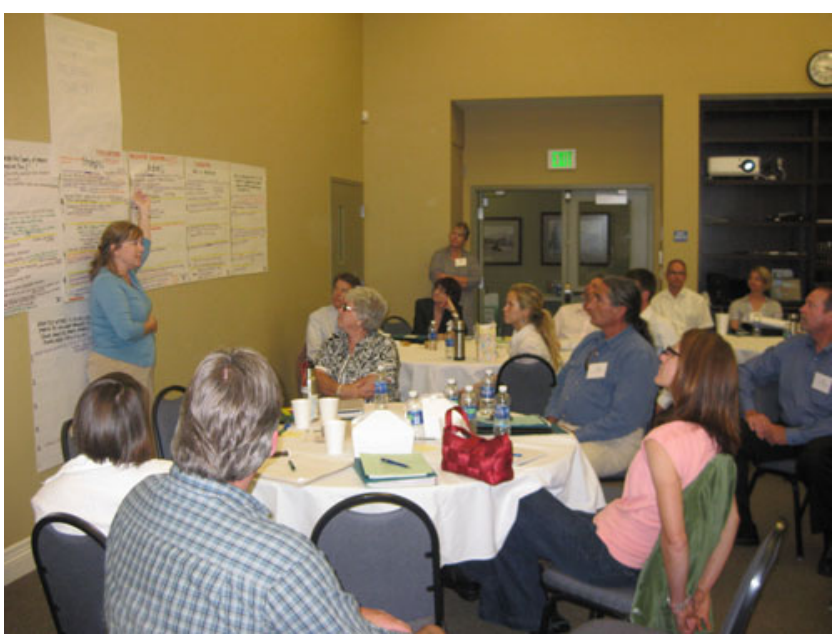

Fig. 2 Break-out group rapporteur during the SLO social systems workshop reporting back to the whole group (photo: Kate Meis)

and who would be the lead actor(s) to implement them. A prioritization exercise and workshop debrief concluded the event. Among the many appreciative comments, one participant's comment received many nods: "I thought we'd be spending all day talking about the depressing and uncertain changes we can expect from global warming. But, instead, we talked about how to create the community we really want."

According to post-workshop surveys (answered by $28.6 \%$ of attendees after two email reminders), the vast majority of survey respondents found the information presented prior to discussions clearly presented, interesting, locally relevant, of appropriate length, and helpful for the day's deliberations (Table 2). In the breakout group discussions themselves, most respondents also agreed or strongly agreed that they learned something new about vulnerability and adaptation, the themes selected for the county were the right ones, the discussion was useful, and that it resulted in overall satisfactory outcomes.

These outcomes were presented again to decisionmakers at the follow-up forum several weeks later (25 participants) and to the 100 or so attendees of the public workshop, all of whom were very engaged and interested in the topic and adaptation options.

\section{Fresno County}

The Fresno social systems workshop was attended by 32 participants. As in SLO, the workshop was hosted and opened by a local city manager; participants also received a briefing on the results of the natural systems workshop and on vulnerability, adaptation, and potential social systems impacts. The day's discussions in this location were related to and framed as extensions of the region's Blueprint rather than focusing solely on local or regional climate policy agendas. The climate change overview was presented by a local climatologist rather than a project team member, a choice based on the desire to involve and build on previous work done by members of the local state university (Harmsen et al. 2008), and to diffuse some of the skepticism of climate change previously directed toward us. Comments on the social systems background report received prior to the workshop reflected not only that attendees may not be familiar with the state of climate change science, but also the contentiousness that the issue evoked among local audiences. Those comments were professionally addressed in writing prior to the workshop, which contributed to very congenial face-to-face interactions between the reviewers and the authors. However, the project team agreed that the issue would be received more easily if presented by a local expert rather than outsider experts.

The deliberations that followed were slightly abbreviated based on the experience in the SLO workshop with participant fatigue and the less-than-successful, somewhat rushed prioritization exercise at the end of a long day of discussions. The structure otherwise was the same. Workshop participants, while maybe less familiar with climate science, were extremely knowledgeable about the social conditions and the infrastructure and environmental issues pertinent to their social and economic systems and community services. Environmental justice issues, water and agriculture vulnerabilities, and public health raised engaged discussions and sophisticated suggestions for adaptation.

Table 3 summarizes the post-workshop feedback we received from $37.5 \%$ of attendees. The results are overall positive, yet somewhat more muted than in SLO. While the small number of responses makes interpretation difficult, we view it as indicative that some participant took the anonymous feedback opportunity to express complete disagreement with the climate science (and/or its interest and relevance to the day's discussion). The link between adaptation and the Blueprint appears to have been unevenly successful, at least during the workshop discussions. And while the selected themes seem to have been of great interest and the most important ones for the county, participants vary considerably in their assessment whether or not the discussion raised all the right issues. Unfortunately, no additional information is available to better understand this spread of responses. Overall, however, the rating of satisfaction with outcomes is only slightly lower than in SLO.

Interestingly, despite initial difficulty in gaining interest for the project in Fresno among community leaders, the skepticism of the background reports and climate science, and the somewhat lower enthusiasm expressed in the survey, local leadership was extremely gracious and expressly grateful for being one of the two pilot studies 
Table 2 SLO social systems workshop attendees' feedback $(n=12)$

\begin{tabular}{|c|c|c|c|c|c|}
\hline Questions (abbreviated) & Strongly agree $(\%)$ & Agree $(\%)$ & $\begin{array}{l}\text { Neither agree } \\
\text { or disagree }(\%)\end{array}$ & Disagree $(\%)$ & $\begin{array}{l}\text { Strongly } \\
\text { disagree }(\%)\end{array}$ \\
\hline \multicolumn{6}{|l|}{ Climate change and natural systems summary } \\
\hline Clear presentation of information & 41.7 & 50 & 8.3 & 0 & 0 \\
\hline Information locally relevant & 41.7 & 41.7 & 16.7 & 0 & 0 \\
\hline Engaging and interesting & 41.7 & 41.7 & 8.3 & 8.3 & 0 \\
\hline Helpful for day's discussions & 33.3 & 50 & 8.3 & 8.3 & 0 \\
\hline Just the right length & 41.7 & 50 & 0 & 8.3 & 0 \\
\hline \multicolumn{6}{|l|}{ Social system vulnerabilities and adaptation } \\
\hline Clear presentation of information & 66.7 & 33.3 & 0 & 0 & 0 \\
\hline Information locally relevant & 58.3 & 25 & 16.7 & 0 & 0 \\
\hline Engaging and interesting & 75 & 16.7 & 8.3 & 0 & 0 \\
\hline Helpful for day's discussions & 58.3 & 25 & 16.7 & 0 & 0 \\
\hline Just the right length & 41.7 & 58.3 & 0 & 0 & 0 \\
\hline \multicolumn{6}{|l|}{ Connection to local mitigation efforts } \\
\hline Engaging and interesting & 41.7 & 41.7 & 16.7 & 0 & 0 \\
\hline Helpful for day's discussions & 33.3 & 50 & 16.7 & 0 & 0 \\
\hline \multicolumn{6}{|l|}{ Break-out group themes } \\
\hline Of interest to me & 75 & 25 & 0 & 0 & 0 \\
\hline Relevant to the county & 83.3 & 16.7 & 0 & 0 & 0 \\
\hline Raised most important issues & 50 & 41.7 & 8.3 & 0 & 0 \\
\hline Topics were clearly enough defined & 18.2 & 72.7 & 8.3 & 0 & 0 \\
\hline \multicolumn{6}{|l|}{ Break-out group discussions } \\
\hline Vulnerability discussion was useful & 50 & 50 & 0 & 0 & 0 \\
\hline $\begin{array}{l}\text { I learned something new about } \\
\text { vulnerability }\end{array}$ & 58.3 & 33.3 & 8.3 & 0 & 0 \\
\hline Flow of discussion was helpful & 41.7 & 58.3 & 0 & 0 & 0 \\
\hline Adaptation discussion was useful ${ }^{\mathrm{a}}$ & 27.3 & 45.5 & 9.1 & 0 & 0 \\
\hline $\begin{array}{l}\text { I learned something new about } \\
\text { adaptation }^{\text {a }}\end{array}$ & 33.3 & 41.7 & 0 & 8.3 & 0 \\
\hline Overall pleased with outcomes & 50 & 41.7 & 0 & 8.3 & 0 \\
\hline Overall importance of workshop themes & $\begin{array}{l}\text { Extremely } \\
\text { important }(\%)\end{array}$ & $\begin{array}{l}\text { Important } \\
(\%)\end{array}$ & $\begin{array}{l}\text { Neither } \\
\text { un/important (\%) }\end{array}$ & $\begin{array}{l}\text { Unimportant } \\
\quad(\%)\end{array}$ & $\begin{array}{l}\text { Completely } \\
\text { unimportant (\%) }\end{array}$ \\
\hline Water supply/wastewater & 91.7 & 8.3 & 0 & 0 & 0 \\
\hline Health/emergency preparedness & 41.7 & 58.3 & 0 & 0 & 0 \\
\hline Infrastructure & 66.7 & 16.7 & 16.7 & 0 & 0 \\
\hline Agriculture and related tourism & 58.3 & 41.7 & 0 & 0 & 0 \\
\hline Coastal/marine/related tourism & 41.7 & 58.3 & 0 & 0 & 0 \\
\hline
\end{tabular}

${ }^{a}$ Survey respondents also had an "n/a" answer option, which was only used in two instances. Hence the percentages here do not add to $100 \%$

selected for the project. This was reiterated by the 27 participants in the Fresno decision-maker forum in late October 2010. Participants, in post-event feedback, judged it as "an extremely valuable process" and appreciated the "opportunity to dialogue on this important issue." At the same time, attendees acknowledged that "to get meaningful engagement on the subject of climate change by policy makers in our area will take time and patience" and many of the intractable issues require not just information but "resources to deal with them" and state-level involvement.

Evidence of attitude changes and adaptation progress

From follow-up discussions with key leaders from both SLO and Fresno counties, it is apparent that the workshop series overall was well received. It is too soon to assess the full impact of the workshop series as both counties are still in the process of determining policy options, but both counties are taking next steps that stem from or connect with the climate change adaptation workshop series.

\section{SLO County}

According to county contacts interviewed in December 2010, several months after the adaptation workshop series, local government leaders have expressed interest in including the adaptation strategies developed by stakeholders in the regional sustainable communities strategy currently under development. This regional plan aims primarily at greenhouse gas emissions reductions through 
Table 3 Fresno social systems workshop attendees' feedback ( $n=12$, unless otherwise noted)

\begin{tabular}{|c|c|c|c|c|c|}
\hline $\begin{array}{l}\text { Questions } \\
\text { (abbreviated) }\end{array}$ & $\begin{array}{l}\text { Strongly } \\
\text { agree }(\%)\end{array}$ & $\begin{array}{l}\text { Agree } \\
(\%)\end{array}$ & $\begin{array}{l}\text { Neither agree or } \\
\text { disagree }(\%)\end{array}$ & $\begin{array}{l}\text { Disagree } \\
(\%)\end{array}$ & $\begin{array}{l}\text { Strongly } \\
\text { disagree }(\%)\end{array}$ \\
\hline \multicolumn{6}{|l|}{ Climate change summary } \\
\hline Engaging and interesting & 50 & 33.3 & 8.3 & 0 & 8.3 \\
\hline Helpful for day's discussions & 41.7 & 50 & 0 & 0 & 8.3 \\
\hline \multicolumn{6}{|l|}{ Natural systems summary } \\
\hline Clear presentation of information & 63.6 & 36.4 & 0 & 0 & 0 \\
\hline Information locally relevant & 50 & 41.7 & 8.3 & 0 & 0 \\
\hline Engaging and interesting & 50 & 41.7 & 0 & 8.3 & 0 \\
\hline Helpful for day's discussions & 58.3 & 25 & 0 & 16.7 & 0 \\
\hline Just the right length & 41.7 & 33.3 & 8.3 & 8.3 & 8.3 \\
\hline \multicolumn{6}{|l|}{ Social system vulnerabilities and adaptation ${ }^{a}$} \\
\hline $\begin{array}{l}\text { Clear presentation of } \\
\text { information }\end{array}$ & 50 & 33.3 & 8.3 & 0 & 0 \\
\hline Information locally relevant & 50 & 33.3 & 8.3 & 0 & 0 \\
\hline Engaging and interesting & 50 & 33.3 & 8.3 & 0 & 0 \\
\hline Helpful for day's discussions & 50 & 33.3 & 8.3 & 0 & 0 \\
\hline Just the right length & 33.3 & 41.7 & 16.7 & 0 & 0 \\
\hline \multicolumn{6}{|l|}{ Connection to local Blueprint $^{\mathrm{a}}$} \\
\hline Engaging and interesting & 25 & 41.7 & 16.7 & 8.3 & 0 \\
\hline Helpful for day's discussions & 16.7 & 41.7 & 25 & 8.3 & 0 \\
\hline \multicolumn{6}{|l|}{ Break-out group themes } \\
\hline Of interest to me & 60 & 30 & 10 & 0 & 0 \\
\hline Relevant to the county & 77.8 & 22.2 & 0 & 0 & 0 \\
\hline Raised most important issues & 33.3 & 33.3 & 22.2 & 11.1 & 0 \\
\hline $\begin{array}{l}\text { Topics were clearly enough } \\
\text { defined }\end{array}$ & 22.2 & 66.7 & 0 & 11.1 & 0 \\
\hline \multicolumn{6}{|l|}{ Break-out group discussions $(n=10)$} \\
\hline $\begin{array}{l}\text { Vulnerability discussion was } \\
\text { useful }\end{array}$ & 30 & 50 & 20 & 0 & 0 \\
\hline $\begin{array}{l}\text { I learned something new about } \\
\text { vulnerability }\end{array}$ & 30 & 50 & 20 & 0 & 0 \\
\hline Flow of discussion was helpful & 30 & 50 & 10 & 10 & 0 \\
\hline $\begin{array}{l}\text { Adaptation discussion was } \\
\text { useful }\end{array}$ & 30 & 30 & 40 & 0 & 0 \\
\hline $\begin{array}{l}\text { I learned something new about } \\
\text { adaptation }\end{array}$ & 30 & 50 & 20 & 0 & 0 \\
\hline Overall pleased with outcomes & 30 & 50 & 20 & 0 & 0 \\
\hline Overall importance of workshop themes & $\begin{array}{l}\text { Extremely } \\
\text { important }(\%)\end{array}$ & $\begin{array}{l}\text { Important } \\
(\%)\end{array}$ & $\begin{array}{l}\text { Neither } \\
\text { un/important }(\%)\end{array}$ & $\begin{array}{l}\text { Unimportant } \\
(\%)\end{array}$ & $\begin{array}{l}\text { Completely } \\
\text { unimportant }(\%)\end{array}$ \\
\hline Water supply/wastewater & 100 & 0 & 0 & 0 & 0 \\
\hline $\begin{array}{l}\text { Health/flooding/emergency } \\
\text { preparedness }\end{array}$ & 55.6 & 44.4 & 0 & 0 & 0 \\
\hline Infrastructure & 55.6 & 44.4 & 0 & 0 & 0 \\
\hline Agriculture and related tourism & 87.5 & 12.5 & 0 & 0 & 0 \\
\hline
\end{tabular}

${ }^{a}$ Survey respondents also had an "n/a" answer option, which was only used in two instances. Hence the percentages here do not add to $100 \%$

transportation planning, but offers opportunities to include several of the adaptation strategies suggested. This presents an exciting opportunity to create a model for how to integrate adaptation with greenhouse gas mitigation.

In addition, the County Board of Supervisors invited LGC's Kate Meis to return to SLO in early November to present to them about the workshop series. This presentation included a summary of the process, highlighted the main socioeconomic strategies developed, and suggested next steps, encouraging them to work adaptation into existing planning and decision-making process- es, such as the Energy Upgrade California Program (http://www.energyupgradecalifornia.org/), general plan updates, the Climate Action Plan, changing zoning codes, and building climate change projections into future development. Following the presentation, high-level county agency directors (some of whom participated in the workshops) expressed interest in taking the strategies developed with stakeholders and turning them into a chapter of their Climate Action Plan. Although it is clearly too early to tell what the long term effects will be of the workshop series, immediate indications of interest in 
adaptation, continued consultation of project leaders, and expressed interest in using the results from the workshop series in official planning efforts suggest that the project achieved or has laid a foundation for achieving its three main project goals.

If policy change requires problems, solutions, and windows of opportunity to come together synchronistically, the timing of this project was "just right." Through careful and intentional building of trustful relationships between the project team, city and county officials, and a local consulting firm working for the county, skillful framing, and alignment of this project with the ongoing climate action planning process, the adaptation workshop series became embedded in an already ongoing locally directed and owned effort. This project provided resources for bringing stakeholders together for public dialog and offered locally relevant information about adaptation. While added after the initial policy development had already begun, our offering arrived at a time that still allowed local leaders to fully own it as an integral part of their efforts. Through separate funding, the developed ideas now have a chance to be taken up in continued policy development, which not only extends the shelf life of the project, but in fact offers an opportunity to develop a model approach to integrated climate policy.

\section{Fresno County}

At the time of project initiation in Fresno, the County was not engaged in any form of climate policy development, but had recently completed a regional planning effort aimed at avoiding further sprawl, loss of valuable agricultural land, air pollution, traffic congestion, and generally improved economic sustainability of California's San Joaquin Valley. While its largest population center, the City of Fresno, had requested a report on potential climate change impacts from local experts, and the City itself had developed plans to reduce its greenhouse gas emissions, little public discussion had ensued on the topic given the general skepticism of the reality of climate change. Consequently, the title of the report on social systems vulnerabilities prepared for Fresno County referenced the goals of the regional Blueprint, and framed climate variability and change as one of multiple stressors with adaptation merely an extension of existing policies aimed at improving the region's sustainability. Preworkshop feedback on that report revealed just how skeptical even local leaders are of climate change, yet the framing of the issue through the vulnerability, economic vitality and sustainability lens ultimately proved useful.

According to one local government official interviewed after the adaptation workshop series in Fresno, "It [the project] provided good support for bringing more people to the table who had not been in the conversation before. It especially helped add credibility that it was done by the Local Government Commission rather than the City." As seems quite common in situations where discourse is contentious and positions hardened, an outside source of information or impulse can open up the discussion in a new way and reenergize it to move beyond seemingly intractable impasses (e.g., Moser 2006; Vogel et al. 2007).

While the climate change discussions this project afforded remained confined to invited stakeholders and decision-makers in Fresno County, engagement of all involved was - contrary to expectation given the political climate-very congenial, sophisticated, and constructive. Several opportunities are emerging that may allow the adaptation process to continue. LGC will be involved in at least two of these recently federal and state-funded efforts aimed at supporting sustainable community strategy planning and water quality improvement. LGC thus has the opportunity to ensure that the strategies identified in this project are known to planners and stakeholder involved in these upcoming processes.

\section{Conclusions}

In summary, we conclude with cautious optimism that the approach taken in this project was an effective "conversation opener" in communities not previously engaged in adaptation planning (in the case of SLO) or where political support to address climate change was low (as in the case of Fresno). Local leaders expressed appreciation and pride in being chosen as one of the pilot communities for this participatory adaptation planning process. Moreover, the project was designed to give local leaders a chance to take ownership of the process and of the issue, and they did.

High response rate to invitations, successful involvement of key community leaders, repeated attendance by those leaders and stakeholders of the entire workshop series, and survey indications of substantive learning suggest that the project succeeded in raising interest in adaptation planning and increasing understanding of adaptation and that it is needed as much as mitigation. Clearly, the project succeeded in developing an initial set of adaptation strategies for key climate-sensitive sectors out of the dialogue between local and external experts and a broad range of stakeholders (Welp et al. 2006), thus also presenting a model for just the kind of process the National Research Council (2010a) called for. While it is too early to report on implementation success, in each of the locations policy and planning processes are continuing, allowing the conversation about climate change adaptation to advance. Thus we are hopeful that the momentum for proactive adaptation will be sustained. Clearly, a stakeholder engage- 
ment process like the one described here alone will not lead to changes on the ground. State and federal funding is proving essential in maintaining interest and moving the policy agenda forward. At the same time, the various phases of stakeholder involvement give adaptation more prominence, the discussions proved fruitful in engaging a wide range of local expertise - enhanced by outside expertise (Bradshaw 2003), and it created a sense of expectation and accountability among local leaders and stakeholders.

The project paid particular attention to the question of how to frame adaptation in specific local political contexts. This careful strategy, together with professional interaction and frank dialog appears to have paid off in terms of building trust, enabling a conversation, and finding ways to link adaptation to policy opportunities (Peters et al. 1997). In SLO, we emphasized the complementarity and overlaps between the mitigation planning already underway and our focus, adaptation; in Fresno, we avoided leading with climate change, but emphasized the link between the Blueprint and adaptation as an extension of those previous planning efforts.

In addition to the formal project goals, we also hoped to learn whether or not local officials and stakeholders would be able to quickly pick up on and adopt an unfamiliar social science concept like vulnerability. Workshop observations suggest that this was indeed possible, and where there was slightly more time (as in SLO), it worked even more effectively than with less. Post-workshop surveys indicated that respondents found that concept helpful and learned something new from it. Finally, we were interested to see how useful vulnerability is as a way to frame discussions about adaptation options, especially in politically contentious or climate change-skeptical settings. Vulnerability and its underlying dimensions initially feared to be "too academic" for stakeholders to grab and work with, proved to be quite easily taken up and useful to structure discussions. Not only did the background research "mirror" to the community its current conditions (Keskitalo 2004), it offered participants an entry into the discussion (as local experts on their own communities) that climate change science (as the sphere of expertise of scientists, and as the contentious battleground for value differences) does not. Most importantly, it focused local stakeholders' attention on creating "the community we want to have" rather than on the perceived uncertainty and discouraging news of climate science.

Open Access This article is distributed under the terms of the Creative Commons Attribution Noncommercial License which permits any noncommercial use, distribution, and reproduction in any medium, provided the original author(s) and source are credited.

\section{References}

Allen KM (2006) Community-based disaster preparedness and climate adaptation: local capacity-building in the Philippines. Disasters 30(1):81-101

Armitage DR (2005) Collaborative environmental assessment in the Northwest Territories, Canada. Environ Impact Assess Rev 25 (3):239-258

Bradshaw B (2003) Questioning the credibility and capacity of community based resource management. The Canadian Geographer/Le Géographe Canadien 47(2):137-150

Brody S, Grover H, Lindquist E, Vedlitz A (2010) Examining climate change mitigation and adaptation behaviours among public sector organisations in the USA. Local Environment. The Int $\mathrm{J}$ of Justice and Sustain 15(6):591-603

Brunner RD, Lynch AH (2010) Adaptive governance and climate change. American Meteorological Society, Boston

Cohen SJ (1997) Scientist-stakeholder collaboration in integrated assessment of climate change: lessons from a case study of Northwest Canada. Environ Model Assess 2(4):281-293

Council of Fresno County Governments (2009) San Joaquin Valley Blueprint: Fresno County Progress Report 2009. Fresno, Fresno COG. Available at: www.valleyblueprint.org

Cutter SL, Boruff BJ, Shirley WL (2003) Social vulnerability to environmental hazards. Soc Sci Quart 84(1):242-261

Dumaru P (2010) Community-based adaptation: Enhancing community adaptive capacity in Druadrua Island, Fiji. Wiley Interdiscip Rev Clim Change 1:751-763

Ebi KL, Semenza JC (2008) Community-based adaptation to the health impacts of climate change. Am J Prev Med 35(5):501-507

Few R, Brown K, Tompkins EL (2007) Public participation and climate change adaptation: avoiding the illusion of inclusion. Clim Policy 7(1):46-59

Frazier TG, Wood N, Yarnal B (2010) Stakeholder perspectives on land-use strategies for adapting to climate-change-enhanced coastal hazards: Sarasota, Florida. Appl Geogr 30(4):506-517

Harmsen F, Hunsaker D, Van de Water P, Luo YV (2008) Mitigation and adaptation strategies for climate change in Fresno California. Institute of Climate Change Oceans and Atmosphere, California State University, Fresno. Available at: http://www.csufresno.edu/ icoa/projects/fresnoclimate.shtml

Huq S, Reid H (2007) Community-based adaptation: a vital approach to the threat climate change poses to the poor. IIED Briefing Paper. International Institute for Environment and Development, London

Keskitalo ECH (2004) A framework for multi-level stakeholder studies in response to global change. Local Environ 9(5):425-435

Knowles N (2009) Potential inundation due to rising sea levels in the San Francisco Bay region. PIER research report, CEC-500-2009023-D. California Energy Commission Sacramento, CA

Koopman, ME, Nauman RS, Leonard, JL (2010a) Projected future climatic and ecological conditions in San Luis Obispo County. The National Center for Conservation Science and Policy. Available at: http://www.lgc/adaptation/slo/

Koopman, ME, Nauman RS, Leonard, JL (2010b) Future climate conditions in Fresno County and surrounding counties. The National Center for Conservation Science and Policy. Available at: http://www.lgc.org/adaptation/fresno

Moser SC (2006) Climate change and sea-level rise in Maine and Hawai'i: the changing tides of an issue domain. In: Mitchell RB, Clark WC, Cash DW, Dickson N (eds) Global environmental assessments: information, institutions, and influence. MIT Press, Cambridge, pp 201-239

Moser SC (2009a) Good morning, America! The explosive US awakening to the need for adaptation. California Energy 
Commission and NOAA-Coastal Services Center, Sacramento and Charleston, p 50

Moser SC (2009b) Making a difference on the ground: the challenge of demonstrating effectiveness of decision support. Clim Chang 95:11-21

Moser SC, Ekstrom JA (2010a) Developing adaptation strategies for San Luis Obispo County: preliminary climate change vulnerability assessment for social systems. Technical report prepared for the Local Government Commission, Sacramento, CA. Available at: http://www.lgc.org/adaptation/slo/

Moser SC, Ekstrom JA (2010b) Toward a vibrant, prosperous and sustainable Fresno County: vulnerability and adaptation to rapid change. Technical report prepared for the Local Government Commission, Sacramento, CA. Available at: http:/www.lgc.org/ adaptation/fresno/

National Research Council (2008) Public participation in environmental assessment and decision making. National Academies Press, Washington

National Research Council (2010a) America's climate choices: adapting to the impacts of climate change. National Academies Press, Washington

National Research Council (2010b) America's climate choices: advancing the science of climate change. National Academies Press, Washington

National Research Council (2010c) America's climate choices: informing an effective response to climate change. National Academies Press, Washington

Peters RG, Covello VT, McCallum DB (1997) The determinants of trust and credibility in environmental risk communication: an empirical study. Risk Anal 17(1):43-54

Reid H, Alam M, Berger R, Cannon T, Huq S, Milligan A (eds) (2009) Special issue: community-based adaptation to climate change. Particip Learn and Action 60

Research Department of the San Luis Obispo Chamber of Commerce (SLOCC) (2009) Community economic profile for the city of
San Luis Obispo (with additional information about San Luis Obispo County). Available at: http://slochamber.org/Library/ PDFs/2010CommunityEconomicProfile.pdf

Ridder D, Pahl-Wostl C (2005) Participatory integrated assessment in local level planning. Reg Environ Chang 5:188-196

Roberts D (2010) Prioritizing climate change adaptation and local level resilience in Durban, South Africa. Environ and Urban 22 (2):397-413

Salter J, Robinson J, Wiek A (2010) Participatory methods of integrated assessment - a review. Wiley Interdiscip Rev Clim Change 1:697-717

Shackley S, Deanwood R (2002) Stakeholder perceptions of climate change impacts at the regional scale: implications for the effectiveness of regional and local responses. J Environ Plan Manag 45(3):381-402

Shaw A, Sheppard S, Burch S, Flanders D, Wiek A, Carmichael J, Robinson J, Cohen S (2009) Making local futures tangiblesynthesizing, downscaling, and visualizing climate change scenarios for participatory capacity building. Glob Environ Chang 19(4):447-463

van Aalst MK, Cannon T, Burton I (2008) Community level adaptation to climate change: the potential role of participatory community risk assessment. Glob Environ Change 18(1):165-179

Vogel C, Moser SC, Kasperson RE, Dabelko GD (2007) Linking vulnerability, adaptation, and resilience science to practice: pathways, players, and partnerships. Glob Environ Chang 17(34):349-364

Warburton D, Wilson R, Rainbow E (2011) Making a difference: a guide to evaluating public participation in central government. Involve, London. Available at: http://www.involve.org.uk/assets/ Uploads/Making-a-Difference-.pdf

Welp M, de la Vega-Leinert A, Stoll-Kleemann S, Jaeger CC (2006) Science-based stakeholder dialogues: theories and tools. Glob Environ Chang 16:170-181 